\title{
De-escalation Strategies for COVID-19 Financial Fraud
}

\author{
Dr. Vasudev Das \\ Walden University, United States
}

\begin{abstract}
COVID-19 financial fraud escalation resulted in the United States' loss of $\$ 87.68$ million to fraudsters within six months. Grounded by the frameworks of Hirschi's social control and Prabhupada's sonic therapeutic intervention, the purpose of this qualitative case study is to explore de-escalation strategies for COVID-19 financial fraud in New York. The data collection methods were semi-structured interviews of purposeful samples and document reviews, which were analyzed utilizing the constant comparative method. The emerged themes are background check, the maximum penalty for offenders, information sharing, public awareness campaigns, education and training, and cybersecurity. The implication for positive social change includes the potential for enhanced management of COVID-19 financial fraud.
\end{abstract}

Keywords: Cheating propensity, Cybersecurity, Education and Training, Public Awareness, Social Control, Sonic Therapeutic Intervention. 